\title{
Delayed postural control during self-generated perturbations in the frail older adults
}

This article was published in the following Dove Press journal:

Clinical Interventions in Aging

28 February 2012

Number of times this article has been viewed

\author{
Alexandre Kubicki ${ }^{1-3}$ \\ François Bonnetblanc ${ }^{1,2}$ \\ Geoffroy Petrement ${ }^{3}$ \\ Yves Ballay ${ }^{1,2}$ \\ France Mourey ${ }^{2,4}$ \\ 'UFR STAPS, Université de \\ Bourgogne, Dijon, France; ${ }^{2}$ Motricité \\ et Plasticité, Institut National de la \\ Santé et de la Recherche Médicale \\ (INSERM), Dijon, France; ${ }^{3}$ SARL Fovea \\ Interactive, Campus Industriel - \\ Espace Entreprises, Chalon sur Saône, \\ France; ${ }^{4}$ UFR Médecine, Université de \\ Bourgogne, Dijon, France
}

Purpose: The aim of this study was to investigate the coordination between posture and movement in pathological aging (frailty) in comparison with normal aging, with the hypothesis that in pathological aging, postural control evolves towards a more reactive mode for which the perturbation induced by the movement is not anticipated and leads to delayed and late postural adjustments.

Methods: Elderly subjects performed rapid focal arm-raising movements towards a target, from an upright standing position in two stimuli conditions: simple reaction time and choice reaction time (CRT). Hand and center of pressure $(\mathrm{CoP})$ kinematics were compared between a control group and a frail group of the same age.

Results: In frail individuals, the entire movement was impaired and slowed down. In addition, postural adjustments that classically precede and accompany the focal arm movement were delayed and reduced, especially in the CRT condition in which the motor prediction is more limited. Finally, a correlation between the time to $\mathrm{CoP}$ maximal velocity and the timed up-and-go score was observed.

Conclusion: In these patients, it was concluded that the control of the CoP displacement evolved from a proactive mode in which the perturbation associated with the arm movement is anticipated toward a more reactive mode in which the perturbation is compensated by late and delayed adjustments.

Keywords: frailty, anticipatory postural adjustments, backward disequilibrium

\section{Introduction}

Focal arm movement performed from an upright standing position generates mechanical perturbations that require fine control of balance. Classically, certain anticipatory postural adjustments (APAs) are triggered before arm movement to compensate for the upcoming perturbation induced by the focal arm movement itself. ${ }^{1,2}$ These APAs are typical of some level of feed-forward control which is integrated into motor programming and illustrate the brain's ability to predict and compensate for self-generated perturbations.

This coordination is particularly important to help to stabilize the body during everyday activities. ${ }^{3} \mathrm{~A}$ decline with age in the motor programming involved in optimizing coordination between posture and movement has been reported. ${ }^{4}$ More particularly, Man'kovskii et al observed delayed APAs in an older population (90-99 years) and showed that postural muscles were activated synchronously and not before focal arm muscles. ${ }^{5}$ In the same vein, Inglin and Woollacott studied the timing of muscle activation in an arm-raising paradigm for a simple reaction time (SRT) and a choice reaction
INSERM U887, Motricité et Plasticité BP 27877, Campus Universitaire, Université de Bourgogne, 21078 Dijon, France

Tel +33380396767

Fax +33380396702

Email alexandre.kubicki@u-bourgogne.fr 
time (CRT) in elderly subjects. They confirmed this idea, and their results revealed delayed APAs in older participants in the CRT condition only. ${ }^{6}$ These studies suggest that normal aging could affect the brain's ability to coordinate posture and movement efficiently and especially to predict and compensate for self-generated perturbations. Interestingly, some recent results also demonstrate that these APAs may be improved by a specific training program. ${ }^{7}$

In the case of nonoptimal aging, these postural adjustments may be even more impaired and delayed. To further investigate this latter hypothesis, the authors tried to determine whether postural adjustments following an arm movement would be delayed in the frail elderly. Frailty is a general concept used by gerontologists who need a global approach to aging. Frailty describes a "multidimensional syndrome of loss of reserves (energy, physical ability, cognition, health) that gives rise to vulnerability." ${ }^{8}$ Several scales have been established over the past 20 years. ${ }^{8,9}$ For instance, the frailty index (FI) assesses patients by means of eleven standard domains. This index is a clinically sensible and practical scale for geriatricians, based on a routinely used comprehensive geriatric assessment instrument. ${ }^{10}$ Among these domains, two items consider their physical capacities: mobility and balance performances. The FI shows that a global approach is needed to better understand the mechanisms of aging, especially in pathological cases. However, it also shows that physical resources are identified as strong predictors of negative evolution towards a critical phase..$^{11,12}$

Numerous studies have tried to understand mobility and balance impairments during normal aging. ${ }^{13}$ Certain authors have shown balance impairments in the context of pathological aging in faller patients. ${ }^{14}$ Nonetheless, further data are needed to better understand balance control and coordination between posture and movement in the frail elderly.

In particular, the authors of this paper hypothesized that the frail elderly would still be less able to compensate for self-generated perturbation associated with a focal arm movement performed from an upright standing position. More specifically, a reactive mode of postural control should be observed in which arm movement would trigger late postural adjustments and delayed center of pressure (CoP) displacements. To further determine whether predictive capacities of self-perturbations are impaired and lead to reactive postural control, the level of uncertainty was varied in two different conditions. As such, an SRT condition was opposed in which motor programming is specified in advance of the go-signal with a CRT condition in which motor programming is specified after the go-signal.
If delayed postural responses are characteristic of pathological aging, some signs in favor of a more reactive mode of postural control should be observed, especially in the CRT conditions in which the movement characteristics are less well known in advance of the go-signal. Finally, in order to determine whether a reactive mode of postural control is representative of more global functional impairments, the authors tried to correlate delays observed in postural control with the functional capacities of patients measured using a timed up-and-go (TUG) test.

\section{Materials and methods \\ Participants}

A total of 20 adults participated in the present study after giving their written consent. The regional ethics committee of Burgundy approved the experimental protocol, which was carried out in agreement with legal and international requirements (Declaration of Helsinki, 1964). Participants were divided into two groups: (1) the control group (CG) composed of ten elderly subjects, including seven females and three males (mean \pm standard deviation [SD]: $74.8 \pm 1.2$ years; $168.3 \pm 7.3 \mathrm{~cm} ; 66.6 \pm 8.5 \mathrm{~kg}$; TUG $7.8 \pm 0.7$ seconds), and (2) the frail group (FG), composed of ten frail elderly subjects including four females and six males (mean $\pm \mathrm{SD}$ : $76.5 \pm 2.9$ years, $168 \pm 8.1 \mathrm{~cm}, 67.6 \pm 13.2 \mathrm{~kg}$; TUG $21.2 \pm 5.8$ seconds). The TUG score is the duration (in seconds) of the following sequence: to stand up from a chair, walk $3 \mathrm{~m}$, turn back around a mark, walk $3 \mathrm{~m}$, turn back again and sit down on the chair, with natural speed. ${ }^{15}$ All participants were right-handed. Participants of the $\mathrm{CG}$ were dynamic elderly: they were in good health, with normal or corrected vision, and did not present any neurological, muscular, or cognitive disorders. They were retired, practiced regular physical activity ( 1.5 hours 2 days per week) and at least one daily cognitive activity (reading newspapers, crosswords, or literature). Their cognitive capacities were evaluated by means of the Mini-Mental State Examination (MMSE) test (mean score: $28 \pm 1.2$ ). Subjects were included in the FG after a conscientious examination of the medical files, and the diagnosis was made by a geriatrician according to the clinical features of this syndrome. Frailty was defined as a clinical syndrome in which three or more of the following criteria were present: unintentional weight loss, self-reported exhaustion, weakness, slow walking speed, and low physical activity. ${ }^{16}$ These patients did not suffer from any extra-pyramidal, pyramidal syndrome, or peripheral neuropathy. They had no recent orthopedic or traumatic injuries $(<1$ year) and no significant cognitive impairment 
(MMSE mean score: $25.8 \pm 1.54$, cognitive impairments are recognized for values $<24$ ). Characteristics of patients in the FG are given in Table 1.

\section{Apparatus and experimental procedure}

Subjects were asked to perform a rapid pointing task from an upright standing position. At the beginning of the session, clinical tests were performed in order to verify the balance and mental capacities of the subjects. Afterward, the armraising task was explained to the subjects: they stood upright on the force platform (feet were placed on the force plate at a $30^{\circ}$ angle to each other, $15 \mathrm{~cm}$ between the two internal malleoli, the force plate presented two foot imprints that were easy to use with patients), the left arm along the body and the right index finger pointing towards the ground, with an angle between the arm and trunk of between $30^{\circ}$ and $35^{\circ}$. All the subjects were asked to remove their shoes. Subjects were required to keep their eyes fixed on a horizontal bar placed in front of them, placed $2 \mathrm{~m}$ above the floor and $2.5 \mathrm{~m}$ from the platform. Three diodes were arranged on this horizontal bar at $60 \mathrm{~cm}$ intervals. The central diode was exactly in front of the participant's right shoulder.

Subjects were asked to perform their movement under two conditions. In the first condition, the central diode was initially turned off. Subjects were told to point with their index finger towards this central diode as soon as it was turned on (SRT condition). In the second condition, subjects were told to point with their index finger towards a left or right diode which was suddenly turned on. Subjects were unaware of the location (right or left) of the visual stimuli (CRT condition). In both conditions, subjects were told to raise their arm as fast and as accurately as possible and to start as quickly as possible after the appearance of the visual stimuli. During their movement, subjects were asked to keep their elbow straight. They were asked to point precisely at the diode, with their index finger on a virtual line between their eyes and the diode, to remain for a few seconds with their arm in the air, and to move their index finger back towards the initial starting position. Before each trial, the subjects were informed of the stimuli condition in which

Table I Characteristics of patients in the frail group

\begin{tabular}{|c|c|c|c|c|c|c|c|c|c|c|}
\hline Subject & Gender & Age & $\begin{array}{l}\text { Height } \\
(\mathrm{cm})\end{array}$ & $\begin{array}{l}\text { Weight } \\
\text { (kg) }\end{array}$ & $\begin{array}{l}\text { TUG } \\
\text { (s) }\end{array}$ & $\begin{array}{l}\text { Gait } \\
\text { speed }(\mathrm{m} / \mathrm{s})\end{array}$ & $\begin{array}{l}\text { Falls } \\
\text { history }\end{array}$ & MMSE & Chronic diseases & $\begin{array}{l}\text { Number } \\
\text { of drugs }\end{array}$ \\
\hline I & $M$ & 74 & $17 \mid$ & 68 & 28 & 0.39 & 0 & 25 & $\begin{array}{l}\text { High blood pressure, } \\
\text { dyslipemia, hypothyroidism, } \\
\text { vesical instability }\end{array}$ & 6 \\
\hline 2 & $\mathrm{~F}$ & 72 & 157 & 61 & 30 & 0.35 & 2 & 24 & $\begin{array}{l}\text { Arrhythmia, hypothyroidism, } \\
\text { gastroesophageal reflux }\end{array}$ & 6 \\
\hline 3 & $M$ & 78 & 176 & 78 & 16 & 0.65 & I & 28 & $\begin{array}{l}\text { High blood pressure, anxiety, } \\
\text { vitamin deficiency }\end{array}$ & 4 \\
\hline 4 & $M$ & 81 & 174 & 74 & 12 & 0.63 & 0 & 24 & $\begin{array}{l}\text { Aortic valve stenosis, prostate } \\
\text { cancer, dyslipemia, type II } \\
\text { diabetes, high blood pressure, } \\
\text { gastroesophageal reflux }\end{array}$ & 6 \\
\hline 5 & $\mathrm{~F}$ & 80 & 157 & 54 & 24 & 0.6 & 2 & 24 & $\begin{array}{l}\text { Depression, high blood } \\
\text { pressure }\end{array}$ & 4 \\
\hline 6 & $M$ & 77 & 169 & 58 & 18 & 0.61 & 0 & 26 & $\begin{array}{l}\text { Vitamin deficiency, } \\
\text { gastroesophageal reflux }\end{array}$ & 4 \\
\hline 7 & $\mathrm{~F}$ & 75 & 160 & 52 & 25 & 0.48 & 3 & 28 & $\begin{array}{l}\text { Arrhythmia, high blood } \\
\text { pressure, chronic obstructive } \\
\text { pulmonary disease, } \\
\text { hip prosthesis, hypothyroidism, } \\
\text { renal insufficiency }\end{array}$ & 6 \\
\hline 8 & $\mathrm{~F}$ & 73 & 167 & 61 & 15 & 0.66 & 2 & 26 & $\begin{array}{l}\text { Arrhythmia, cataract, } \\
\text { depression, thyroidectomy }\end{array}$ & 4 \\
\hline 9 & $M$ & 77 & 176 & 88 & 21 & 0.58 & 0 & 26 & $\begin{array}{l}\text { Arrhythmia, tachycardia, } \\
\text { hypothyroidism, } \\
\text { hip prosthesis }\end{array}$ & 5 \\
\hline 10 & $M$ & 78 & 176 & 83 & 23 & 0.37 & 3 & 27 & $\begin{array}{l}\text { Colon cancer, high blood } \\
\text { pressure, osteoporosis, } \\
\text { arrhythmia }\end{array}$ & 5 \\
\hline
\end{tabular}


they would perform the movement to follow (SRT or CRT). Subjects performed three trials only in each condition in order to limit any potential learning or re-learning effect; they performed these three trials per condition in a random order.

\section{Data and statistical analysis}

Coordination between posture and movement was assessed by measuring hand and $\mathrm{CoP}$ displacements. The $\mathrm{x}, \mathrm{y}$, and $\mathrm{z}$ displacements of the right index finger were recorded using the Vicon ${ }^{\circledR}$ system (Oxford Metrics Group, Oxford, UK) with three cameras (Sampling rate: $200 \mathrm{~Hz}$ ). The marker was placed on the index fingernail. Postural data were recorded using a seesaw force plate (techno concept ${ }^{\circledR}$, Posturwin software, version P3-03). This force plate was connected to the Vicon system by analogical input in order to synchronize these two signals. The recording of CoP displacement on an $\mathrm{x}$ and $\mathrm{y}$ axis began $600 \mathrm{~ms}$ before the hand movement onset and finished $1000 \mathrm{~ms}$ afterwards. The hand movement onset was taken as the time for which the hand velocity rose above $5 \%$ of the hand maximal velocity, at the beginning of the movement. And similarly, the hand movement offset was calculated when the hand velocity fell below $5 \%$ of the hand maximal velocity, at the end of the movement. The go signal (a light-emitting diode was switched on) was synchronized with the Vicon by means of an analogical input. In this way, the hand reaction times were able to be calculated. All signals were synchronized on the hand movement onset $\left(t_{0}\right)$. The authors focused on the synchronization between the hand and the CoP velocity profiles and on the characteristics of $\mathrm{CoP}$ and hand kinematics (CoP maximal velocity [MV]; CoP time to maximal velocity [TMV]; hand peak velocity [PV]; and hand time to peak velocity [TPV]; see Figure 1). To account for differences in hand movement time between groups, TPV of the hand $\left(\mathrm{NTPV}_{\text {Hand }}\right)$ and the TMV of the CoP NTMV $_{\mathrm{CoP}}$ ) were normalized by dividing these two values by the hand movement time (MT). To further investigate whether postural control was delayed for the FG, the CoP mean velocity was analyzed for different temporal intervals. Four temporal intervals were considered: the baseline (from $t_{0}-600 \mathrm{~ms}$ to $t_{0}-150 \mathrm{~ms}$ ), the APA period (from $t_{0}-150 \mathrm{~ms}$ to $t_{0}$ ), an initial control phase (from $t_{0}$ to $t_{0}+100 \mathrm{~ms}$ ), and a final control phase (hand TMV to hand movement end). On average, it has been demonstrated that feedback motor corrections are not possible before $100 \mathrm{~ms}$ after a visual perturbation occurs. ${ }^{17}$ As a consequence, a period of $t_{0}$ to $t_{0}+100 \mathrm{~ms}$ was chosen as an open-loop and programmed phase that reflected pure feed-forward mechanisms without any possibility for feedback motor corrections.

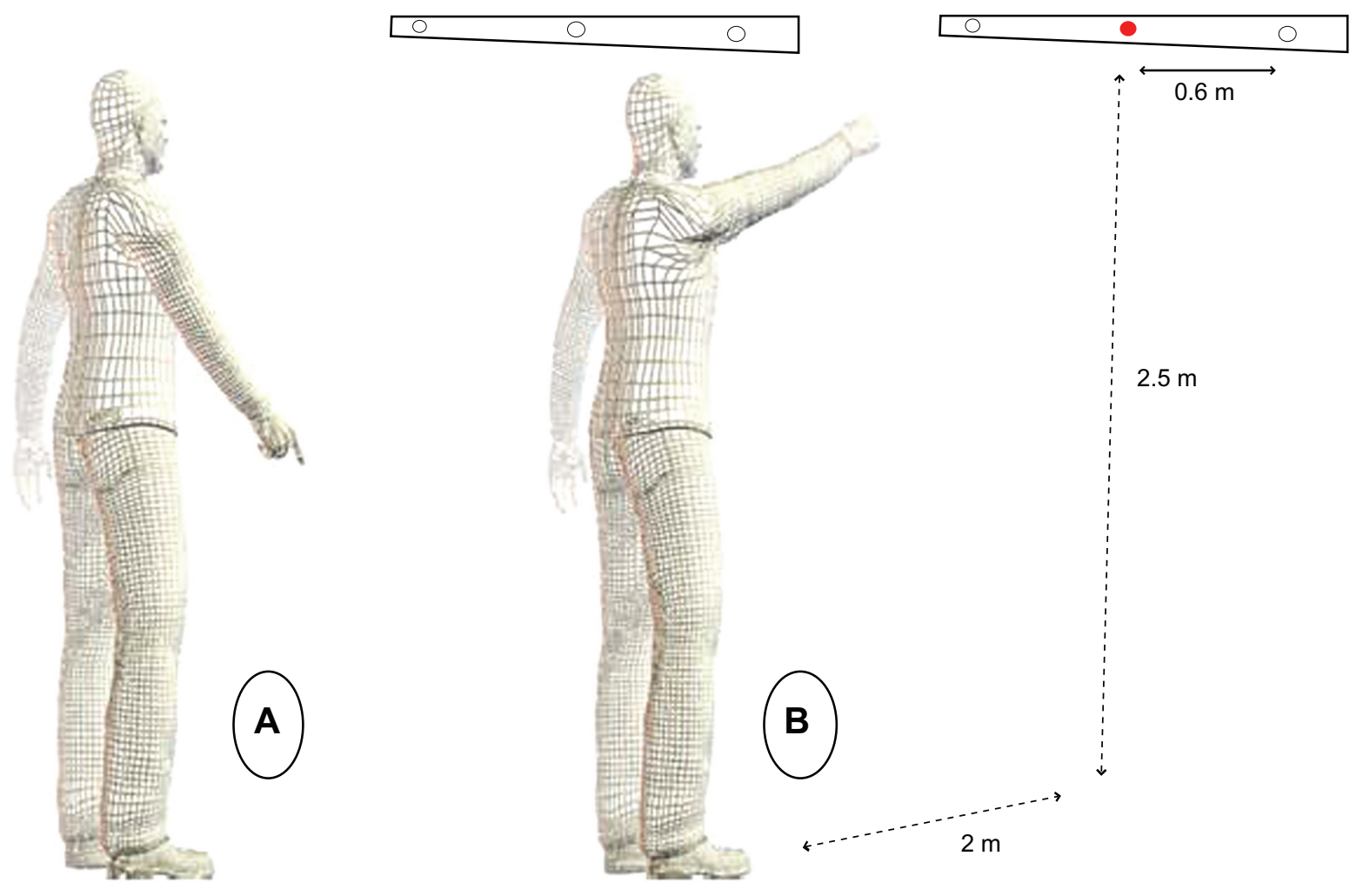

Figure I Representation of the subject position. (A) Position before the go-signal (initial position). (B) Position at the end of the hand movement. 
For these intervals, the mean velocity of the CoP displacement was computed. Mathematically, this parameter was calculated as the integrated function of the $\mathrm{CoP}$ velocity, divided by the interval duration. To take into account the important differences of hand velocity, the mean CoP velocity obtained in the APA period and the initial and final control phases were normalized by dividing these values by the hand mean velocity values. Note that values obtained for the baseline were not normalized, as the $\mathrm{CoP}$ and hand kinematics were independent for this period of time.

The three trials were averaged for each subject. All dependent variables were submitted to two groups (FG and $\mathrm{CG}) \times$ two conditions $(\mathrm{CRT}, \mathrm{SRT})$ analyses of variance (ANOVAs), with repeated measures on the two factors. Levene's test for homogeneity of variance was conducted prior to the analysis of each variable. Post-hoc analyses were conducted using Scheffe's test. All statistical analyses were carried out using an alpha level of 0.05 .

\section{Results}

The three trials in the CRT condition for one subject from each group are presented in Figure 2.

\section{Hand kinematics revealed slower movements for the FG}

To verify that hand movement accuracy in the two groups remained similar, an ANOVA was applied to the $\mathrm{x}, \mathrm{y}$, and $\mathrm{z}$ positions of the hand movement endpoint. Results revealed no main effect of the Group (X: $F[1,18]=0.094, P=0.762$; $\mathrm{Y}: F[1,18]=0.43, P=0.52 ; \mathrm{Z}: F[1,18]=0.134, P=0.718)$ and no Group $\times$ Condition interaction $(\mathrm{X}: F[1,18]=0.013$, $P=0.911 ; \mathrm{Y}: F[1,18]=1.718, P=0.196 ; \mathrm{Z}: F[1,18]=0.067$, $P=0.799)$.

The results did not reveal any statistically significant differences of the final accuracy between the two groups for each condition.

Hand reaction times (hand RTs) were computed as the interval between the appearance of the stimulus and the onset of the hand movement. For this parameter, no main effect of the $\operatorname{Group}(F[1,18]=0.671, P=0.425)$ was noted, but a main effect of the Condition $(F[1,18]=26.971, P<0.001)$ was recorded. When both groups were pooled together, hand RTs were longer for the CRT $(0.406 \pm 0.074)$ than for the SRT $(0.327 \pm 0.071)$. Classically, as the spatial uncertainty about the stimulus location increased, the hand RT increased.

According to Figure 2, hand velocity profiles were flattened for the FG. Hand movements were slowed down with longer hand movement times (hand MT, $F[1,18]=57.976$,
$P<0.001$ ) and lower hand peak velocities (hand PV, $F[1,18]=13.561, P<0.05)$. TPVs were also longer for the FG $\left(\mathrm{TPV}_{\text {Hand, }}, F[1,18]=33.997, P<0.001\right)$. The Group $\times$ Condition interaction was never significant $(P>0.302)$ for any of these parameters. Values for all these parameters in both groups and both conditions are mentioned in Table 2 .

\section{CoP kinematics revealed an initial CoP backward position and a slower CoP displacement for the FG}

Basically, for this type of movement and in normal subjects, the CoP displacement was preceded by an initial backward shift that started before the hand movement onset and was followed by a forward displacement. ${ }^{18}$ After the initial backward displacement of the CoP, both the center of mass and the CoP were displaced more forwardly in relationship to the arm displacement.

This classical pattern of the CoP displacement was clearly challenged for the FG. After a qualitative analysis of all traces for all subjects and as illustrated for these three typical trials of the same subject, several important differences were observed. Firstly, the initial position of the $\mathrm{CoP}$ was deviated more backwardly for the frail subjects compared with the normal subjects. This was confirmed by the statistical analysis: the mean CoP position on the antero-posterior axis, averaged in both conditions of stimuli during the $600 \mathrm{~ms}$ preceding the hand movement onset was more posterior $(F[1,18]=2.282, P=0.001)$ in the FG $(-15.35 \pm 20.9 \mathrm{~mm})$ than in the $\mathrm{CG}(30.27 \pm 31.61 \mathrm{~mm})$.

In addition, the CoP control and especially its forward displacement was much more progressive and slowed down. Results revealed that the CoP MV was lower $(F[1,18]=8.592, P<0.05)$ in the $\mathrm{FG}(\mathrm{SRT}$ : $0.133 \pm 0.073 \mathrm{~m} \cdot \mathrm{s}^{-1} ;$ CRT: $\left.0.114 \pm 0.072 \mathrm{~m} \cdot \mathrm{s}^{-1}\right)$ than in the CG (SRT: $0.209 \pm 0.055 \mathrm{~m} \cdot \mathrm{s}^{-1}$; CRT: $0.2 \pm 0.086 \mathrm{~m} \cdot \mathrm{s}^{-1}$ ). There was no Group $\times$ Condition interaction $(F[1,18]=0.303$, $P=0.588$ ). All of these results are summarized in Table 2 .

\section{CoP kinematics revealed CoP delayed control for the FG}

The CoP MV was analyzed for different temporal intervals to investigate whether the $\mathrm{CoP}$ control was delayed for the FG as could be observed in Figure 3 (please see also the end of the Materials and methods section for more details about the procedure).

Results revealed that during the baseline interval, the CoP MV was superior for the FG. Statistical analysis revealed a main effect of Group $(F[1,18]=6.477, P<0.05)$, no effect 


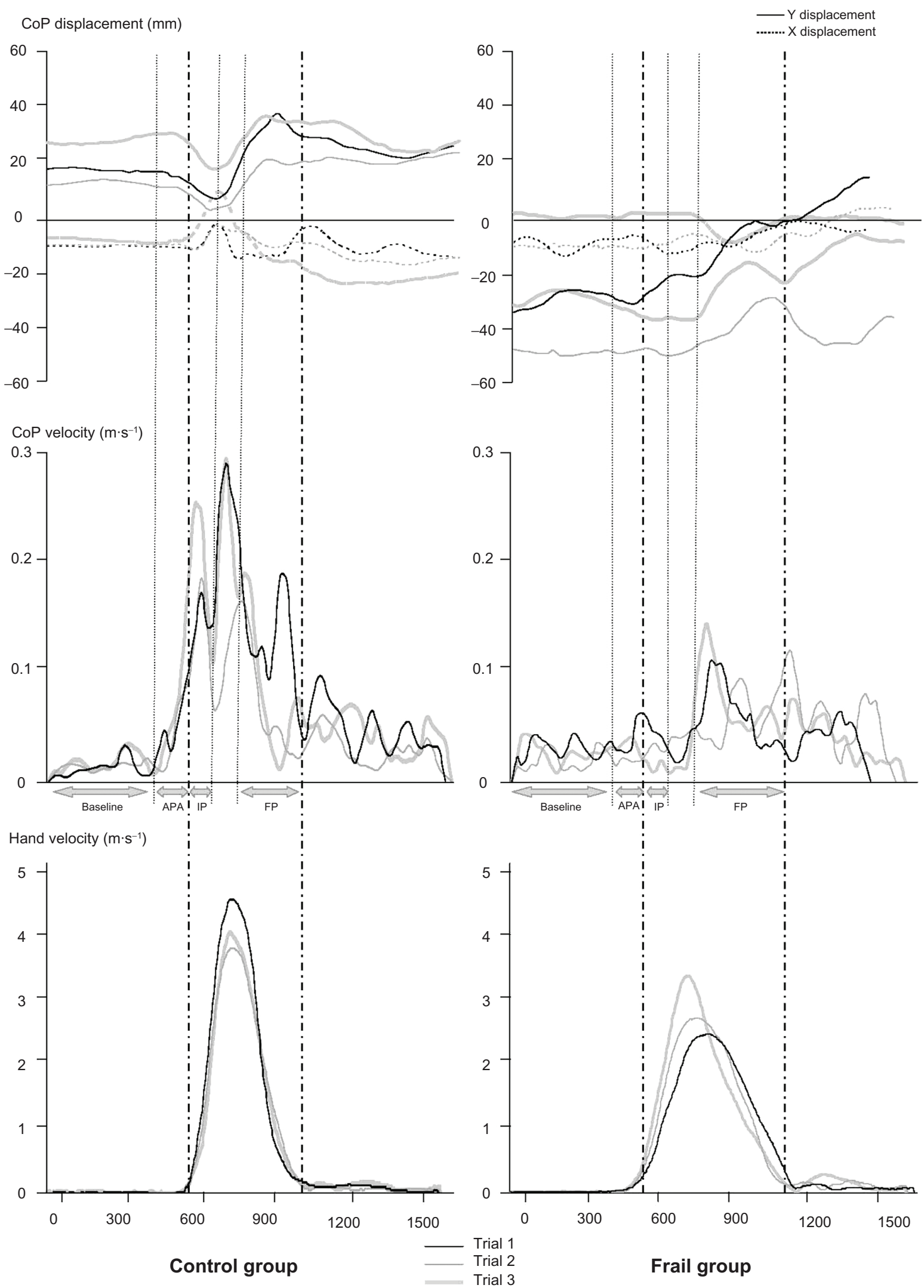

Figure 2 Typical data for two representative subjects (left, control group; and right, frail group) for three trials in the choice reaction time condition. Upper panel: CoP displacement in the medio-lateral axis $(\mathrm{X})$ and antero-posterior axis (Y). Middle panel: CoP velocity profiles. Lower panel: hand velocity profiles. Horizontal axis represents time; acquisition duration is divided into four phases: baseline ( $-600 \mathrm{~ms}$ to $-150 \mathrm{~ms})$; APA phase (-I50 ms to $\left.t_{0}\right)$; IP $\left(t_{0}\right.$ to I00 ms); and FP (between the hand deceleration beginning to the hand movement offset).

Abbreviations: APA, anticipatory postural adjustment; CoP, center of pressure; FP, final phase; IP, initial phase. 
Table 2 Hand and CoP kinematics in the control group and the frail group for the SRT and the CRT conditions

\begin{tabular}{|c|c|c|c|c|c|c|c|}
\hline \multirow[t]{2}{*}{ Parameters } & \multicolumn{2}{|l|}{ SRT } & \multirow{2}{*}{$\frac{P \text {-value }}{\text { Group effect }}$} & \multicolumn{2}{|l|}{ CRT } & \multicolumn{2}{|l|}{$P$-value } \\
\hline & Frail group & Control group & & Frail group & Control group & Group effect & $\begin{array}{l}\text { Group } \times \text { condition } \\
\text { interaction }\end{array}$ \\
\hline Hand RT (s) & $0.326 \pm 0.071$ & $0.329 \pm 0.077$ & 0.931 & $0.382 \pm 0.092$ & $0.431 \pm 0.045$ & 0.162 & 0.305 \\
\hline Hand MT (s) & $0.701 \pm 0.125$ & $0.423 \pm 0.063$ & $<0.001$ & $0.707 \pm 0.104$ & $0.436 \pm 0.057$ & $<0.001$ & 0.746 \\
\hline Hand PV $\left(\mathrm{m} \cdot \mathrm{s}^{-1}\right)$ & $3.513 \pm 0.984$ & $4.689 \pm 0.768$ & 0.008 & $3.189 \pm 0.583$ & $4.6 \pm 0.873$ & $<0.001$ & 0.305 \\
\hline $\operatorname{TPV}_{\text {Hand }}(\mathrm{s})$ & $0.266 \pm 0.068$ & $0.163 \pm 0.018$ & $<0.001$ & $0.262 \pm 0.043$ & $0.175 \pm 0.017$ & $<0.001$ & 0.845 \\
\hline $\operatorname{CoP} M V\left(m \cdot s^{-1}\right)$ & $0.133 \pm 0.073$ & $0.209 \pm 0.055$ & 0.021 & $0.114 \pm 0.072$ & $0.2 \pm 0.086$ & 0.009 & 0.588 \\
\hline $\operatorname{TMV}_{\mathrm{CoP}}(\mathrm{s})$ & $0.342 \pm 0.157$ & $0.151 \pm 0.093$ & 0.004 & $0.499 \pm 0.201$ & $0.149 \pm 0.064$ & $<0.001$ & 0.008 \\
\hline
\end{tabular}

Abbreviations: CoP, center of pressure; CRT, choice reaction time; MT, movement time; MV, maximal velocity; PV, peak velocity; RT, reaction time; SRT, simple reaction time; $\mathrm{TMV}_{\text {CoP }}$, CoP time to maximal velocity; $\mathrm{TPV}_{\text {Hand }}$, hand time to peak velocity.

of Condition $(F[1,18]=1.271, P=0.274)$ and no Group $\times$ Condition interaction $(F[1,18]=0.345, P=0.565)$. This result is illustrated in Figure 3 (left panel, absolute values).

For the APA period, no effect was statistically significant (Group: $F[1,18]=2.549, P=0.128$; Condition: $F[1,18]=0.389, P=0.541$; Group $\times$ Condition interaction: $F[1,18]=0.889, P=0.359)$. This last observation indicates that during the APA phase, CoP displacements were not different between groups.

However, for the initial control phase and the final control phase, the CoP MV was much more superior for the CG than for the FG (main effect of Group: $F[1,18]=11.52, P<0.01$; no effect of Condition: $F[1,18]=0.29, P=0.597$; no Group $\times$ Condition interaction, $F[1,18]=0.16, P=0.693$; and main effect of Group: $F[1,18]=10.96, P<0.01$; no effect of Condition: $F[1,18]=0.47, P=0.5$; and no Group $\times$ Condition interaction, $F[1,18]=0.45, P=0.512$, respectively).
Values for these three last temporal intervals are reported in Figure 3 (right panel). Note that these values were normalized with respect to the hand mean velocity. The FG values obtained in the baseline phase were also compared with those obtained in the APA phase. Results revealed that values obtained during the APA period were not statistically different from those measured during the baseline phase ( $t=1.761, P=0.112$ ). By contrast, values obtained for the baseline phase were different from those measured during the final control phase $(t=3.332, P<0.01)$. Altogether, this last result confirmed the observation made in Figure 2 and showed that the CoP displacement was initiated later for the FG. There is no displacement of the CoP despite the hand movement being initiated.

In addition to this previous important result, an effect of the condition when the CoP TMV was compared between groups was also observed. Indeed, for $\mathrm{TMV}_{\mathrm{CoP}}$,

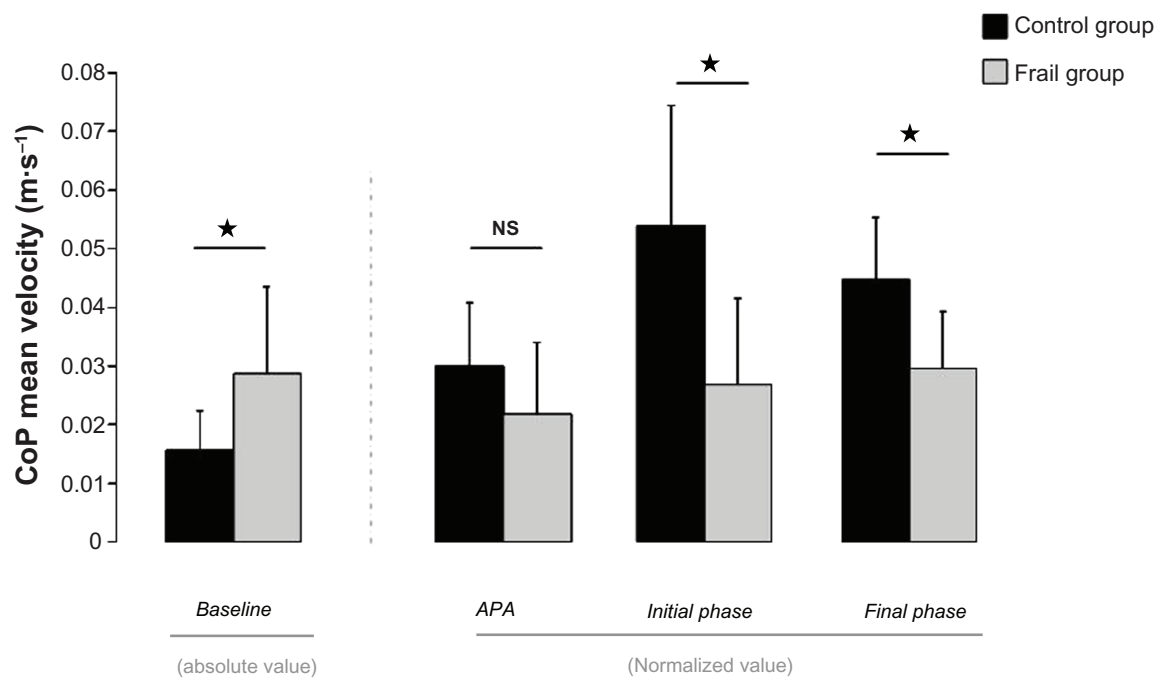

Figure $3 \mathrm{NTPV}_{\text {Hand }}$ and $\mathrm{NTMV}_{\text {CoP }}$ with respect to hand movement time, in the two groups and for the SRT and the CRT conditions. Notes: Standard deviations are represented by vertical bars. Asterisks show a statistical significance of $P<0.05$.

Abbreviations: APA, anticipatory postural adjustment; CoP, center of pressure; CRT, choice reaction time; NTMV ${ }_{\text {CoP }}$ CoP normalized time to maximal velocity; NTPV Hand , hand normalized time to peak velocity; SRT, simple reaction time. 
statistical analysis revealed a main effect of the Group $(F[1,18]=24.797, P<0.001)$, a main effect of Condition $(F[1,18]=6.139, P<0.05)$, and a Group $\times$ Condition interaction $(F[1,18]=6.498, P<0.05)$. $\mathrm{TMV}_{\mathrm{CoP}}$ were longer in the FG in both conditions and to a greater extent in the CRT condition (values are reported in Table 2).

To take into account the great differences between movement durations in the two groups, the TPV $\mathrm{Hand}_{\text {and }} \mathrm{TMV}_{\mathrm{CoP}}$ were normalized by dividing these values by the hand MT.

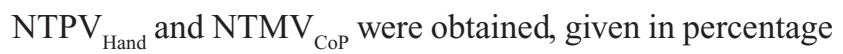
of the hand movement duration. $\mathrm{NTPV}_{\text {Hand }}$ were similar (no main effect of Group: $F[1,18]=0.897, P=0.35$, Condition: $F[1,18]=0.187, P=0.67$, and no Group $\times$ Condition interaction: $F[1,18]=0.368, P=0.55)$ between the FG (SRT: $38 \% \pm 7 \%$; CRT: $37 \% \pm 5 \%$ ) and the CG (SRT: $39 \% \pm 5 \%$; CRT: $40 \% \pm 4 \%$ ).

Results for the $\mathrm{NTMV}_{\mathrm{CoP}}$ showed a significant main effect of Group $(F[1,18]=9.773, P<0.05)$, and a significant Group $\times$ Condition interaction: $F[1,18]=4.63, P<0.05)$ in the FG (SRT: $48 \% \pm 19 \%$; CRT: $69 \% \pm 21 \%$ ) than in the CG (SRT: $36 \% \pm 23 \%$; CRT: $34 \% \pm 15 \%$ ). A decomposition of this interaction revealed that the frail individuals took even more time with respect to the CG to attain a maximal velocity of CoP displacement in the CRT condition compared with the SRT condition. These results are reported in Figure 4.

To sum up, these results thus demonstrated that in proportion of the MT, the CoP Velocity reached its maximal value later for the FG and even more in the CRT condition compared with the SRT condition.

\section{Relationship between TUG scores and CoP kinematics}

To explore whether TUG scores correlate with certain parameters of the CoP kinematics, and to determine whether the task had some measure of functional value, some parameters of the CoP kinematics were plotted as a function of TUG scores for each subject. A significant correlation was found between TUG scores and TMV ${ }_{\mathrm{CoP}}$ in both the CG and the FG ( $r=0.71$ and 0.72 respectively). These correlations are illustrated in Figure 5.

\section{Discussion}

The aim of this study was to determine how frailty may affect posture and movement coordination during a rapid armraising task performed from an upright standing position. In particular, the authors hypothesized that a reactive postural control with delayed postural adjustments would follow the initiation of the arm movement in the frail elderly.

The main results of this study demonstrated that frail individuals performed the entire movement more slowly, and the movement was accompanied with delayed postural adjustments. A slowing down of movement with normal aging has already been reported. ${ }^{19}$ The present study demonstrated that frail individuals performed the arm-raising task even more

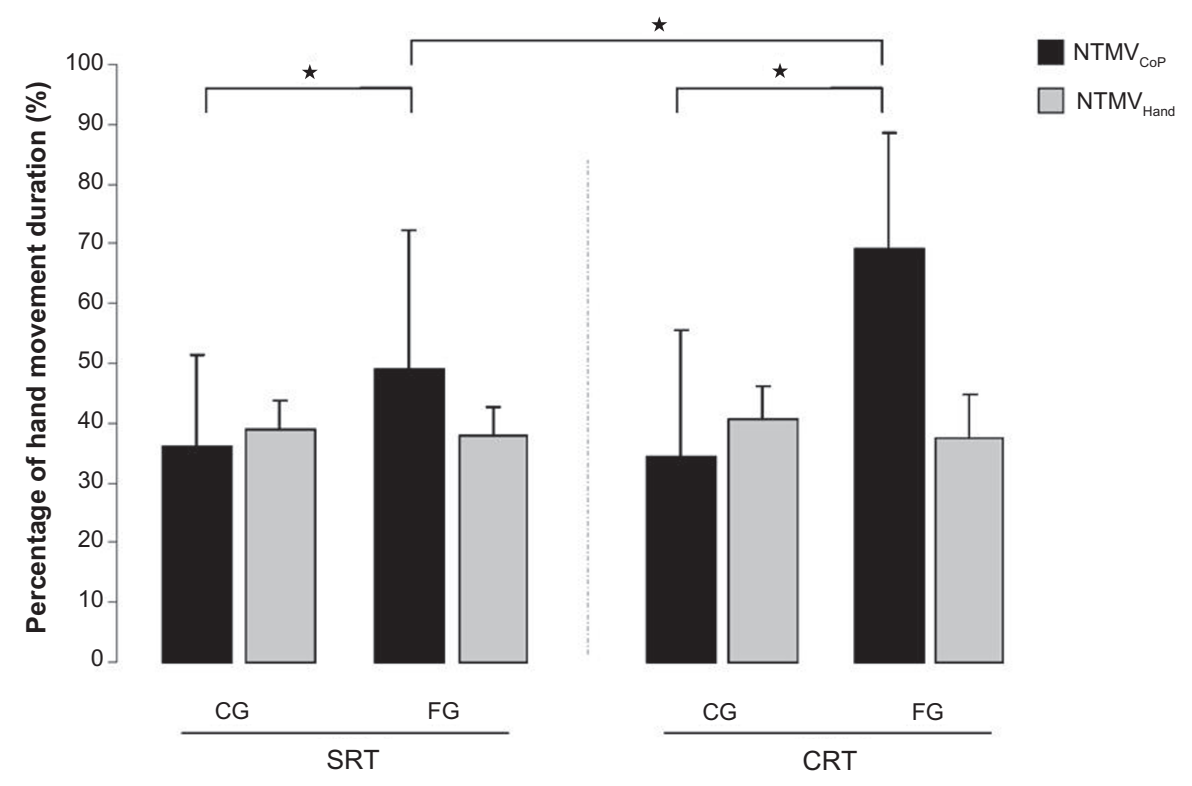

Figure $4 \mathrm{CoP}$ mean velocity during the baseline absolute values (left panel). CoP mean velocity during the APA, initial and final intervals, normalized values (right panel) in the CG and the FG.

Note: Standard deviations are represented by vertical bars. Asterisks show a statistical significance of $P<0.05$.

Abbreviations: APA, anticipatory postural adjustment; CG, control group; CoP, center of pressure; CRT, choice reaction time; FG, frail group; NTMV ${ }_{\text {CoP }}$ CoP normalized time to maximal velocity; $\mathrm{NTMV}_{\text {Hand }}$, hand normalized time to maximal velocity. 


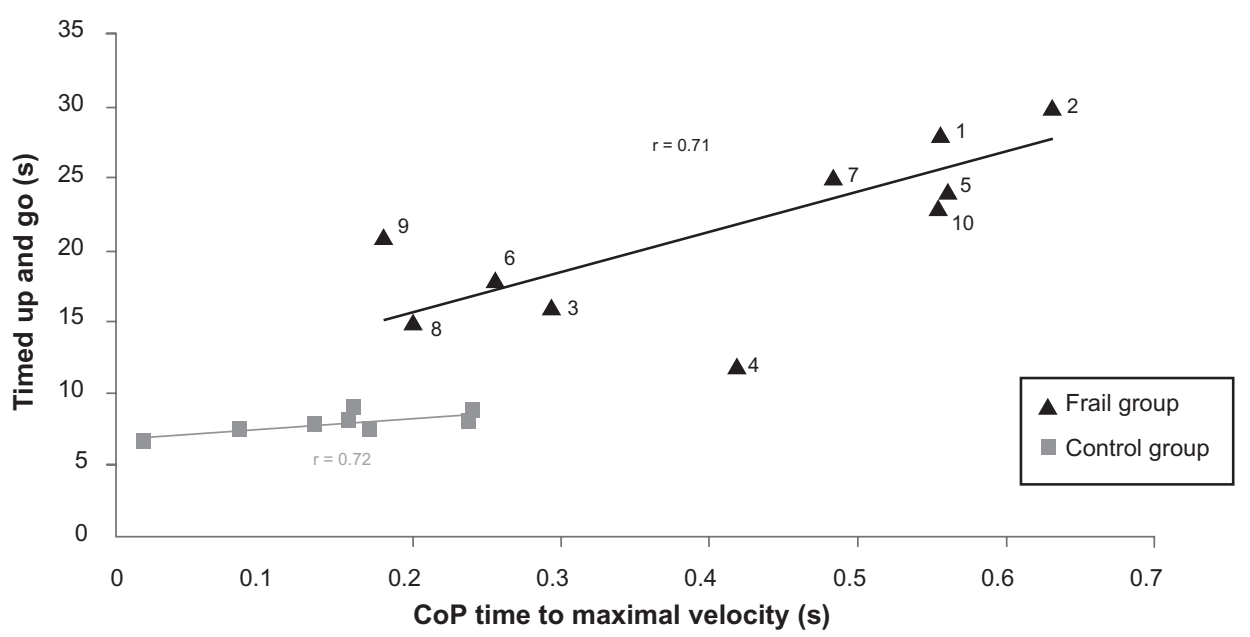

Figure 5 Relationship between timed up-and-go scores and CoP time to maximal velocity in the control group (gray square) and the frail group (black triangle). Abbreviation: CoP, center of pressure.

slowly than normal subjects. More particularly, this general slowing down in frail elderly individuals was accompanied by clear changes in the organization of postural control.

More specifically, results demonstrated that the CoP displacement was initiated later after the arm started to move. Compared to the CG, no APA was noticed in the FG, and even $100 \mathrm{~ms}$ after the initiation of the hand movement, the CoP velocity normalized by the hand velocity did not reveal a substantial CoP displacement (Figure 3). In addition, the CoP displacement during the APA was identical to that observed during the baseline. By contrast, for the $\mathrm{CG}$, the CoP displacement preceded that of the hand. Altogether, it suggests that the postural adjustments are strongly delayed for the FG.

Different initial postural states were also observed between the two groups. During the baseline period and before the hand started to move, the CoP displacement was more important, and its position was located more backwardly for the FG. As commonly observed by geriatricians, frail elderly were unstable compared with control subjects (CoP displacements increase in a standing-upright task), and presented a backward disequilibrium (CoP position more posterior). ${ }^{20}$ As such, one may also interpret that delayed postural adjustments observed for the FG are a consequence of the initial postural state that differs between the two groups.

It seems difficult to isolate the effects of reduced predictive capacities from those linked to the initial postural state. Indeed, as the $\mathrm{CoP}$ is already shifted more backwardly before the arm-raising movement, APA could be more limited in this case. In other words, frail individuals could adapt their behavior and decide to shift their center of mass and CoP more backwardly to compensate a priori for the upcoming forward displacement of the center of mass. However, this adaptation is not realistic for several reasons. First, the constant initial position of these patients is suboptimal because it brings the center of mass and the CoP near the stability margins and induces more important oscillations of the center of mass. ${ }^{21}$ Second, it has been shown that subjects get less and less accurate in their perception of the postural vertical with age, and the internal model of verticality is less robust in elderly people, ${ }^{22}$ especially for patients with backward disequilibrium. ${ }^{20}$ As a whole, it strongly suggests that the delayed postural control observed for these patients is due rather to an inaccurate state estimation and inaccurate predictive processes than a conscious adaptation of their motor strategy.

This interpretation is reinforced when the SRT and CRT conditions were compared. Indeed, it was observed that the CoP MV was reached after the hand peak velocity in frail individuals in both conditions, but later in the CRT. This observation strengthens the authors' hypothesis and suggests that in a condition of more uncertainty and in which the motor programming cannot be specified before the go-signal, frail individuals seem to exhibit a delayed control of their CoP. At this point, it is important to note that this difference between the two groups was independent of the hand velocity and as such revealed that the FG showed a delayed postural control that is even more pronounced with the uncertainty of the perturbation.

As a whole, delayed postural adjustments may illustrate a decrease in the predictive capacities that occur with pathological aging. The frail elderly may be less accurate to predict the perturbation associated with the hand movement and to initiate the postural compensations before the arm 
starts to move. The results of this present study are in line with this interpretation.

Finally, to determine whether this reactive mode of postural control is representative of more global functional impairments, the authors also tried to uncover correlations between the kinematic parameters studied and the functional capacities of the patients used in this study, as measured using the TUG test. The TUG score has been shown to be a reliable test to assess certain functional capacities in elderly individuals, to dissociate between normal and pathological aging, and especially to identify potential fallers. ${ }^{23}$ Interestingly, although the two groups were clearly dissociated, significant correlations were found between the TUG scores and CoP TMV in both the CG and the FG. Two different subgroups and a single subject can be isolated from this correlation. The most impaired group (subjects 1, 2, 5, 7, and 10) with the lowest TUG scores was also the most impaired in gait speed $\left(0.44 \mathrm{~m} \cdot \mathrm{s}^{-1}\right.$ versus $\left.0.62 \mathrm{~m} \cdot \mathrm{s}^{-1}\right)$ and composed of subjects with the most worrisome fall history ( 2 versus 0.75 for the last 6 months) and conversely. The subject (subject 4) that seemed quite different from the two groups showed a good TUG score and gait speed but was among subjects that consume a high number of drugs (six).

Despite a quite important variability, few trials seem sufficient to discriminate functional capacities of frail individuals on the basis of their CoP TMV in a simple arm-raising task. In addition, dynamic equilibrium may share some common characteristics between different tasks, and TUG scores may also be representative of some level of deficiency in frail elderly subjects' predictive capacities.

\section{Conclusion}

Delayed postural responses following self-generated perturbation and reduced predictive capacities seem to be among the signs of pathological aging and to be correlated with functional capacities in frail individuals. These latter may be inaccurate to predict dynamic perturbations linked to the movement execution. These observations were made during a task involving arm movements alone. They should be made in other situations including other types of perturbations to allow more generalization. This approach could have important clinical implications in rehabilitative therapies as aged patients usually fall when moving (dynamic equilibrium) rather than during orthostatic equilibrium. ${ }^{24}$ It has been shown that these predictive capacities could be improved in normal older adults. ${ }^{7}$ In consequence further studies may be interesting to investigate whether frail elderly patients could be also ameliorated by a specific training.

\section{Acknowledgments}

The authors are grateful to the Champmaillot Hospital staff and to the voluntary subjects in both groups.

\section{Disclosure}

The authors report no conflicts of interest in this work.

\section{References}

1. Belen'kiĩ VE, Gurfinkel' VS, Pal'tsev EI. Control elements of voluntary movements [in Russian]. Biofizika. 1967;12:135-141.

2. Massion J. Movement, posture and equilibrium: interaction and coordination. Prog Neurobiol. 1992;38(1):35-56.

3. Woollacott MH. Age-related changes in posture and movement. J Gerontol. 1993;48:56-60.

4. Woollacott MH, Manchester DL. Anticipatory postural adjustments in older adults: are changes in response characteristics due to changes in strategy? J Gerontol. 1993;48:M64-M70.

5. Man'kovskii NB, Mints AYa, Lysenyuk VP. Regulation of the preparatory period for complex voluntary movement in old and extreme old age. Hum Physiol. 1980;6:46-50.

6. Inglin B, Woollacott M. Age-related changes in anticipatory postural adjustments associated with arm movements. J Gerontol. 1988;43:M105-M113.

7. Kubicki A, Petrement G, Bonnetblanc F, Ballay Y, Mourey F. Practicerelated improvements in postural control during rapid arm movement in older adults: a preliminary study. J Gerontol A Biol Sci Med Sci. 2012;67(2):196-203.

8. Rockwood K, Song X, MacKnight C, et al. A global clinical measure of fitness and frailty in elderly people. CMAJ. 2005;30;173:489-495.

9. Bandeen-Roche K, Xue QL, Ferruci L, et al. Phenotype of frailty: characterization in the women's health and aging studies. J Gerontol A Biol Sci Med Sci. 2006;61:262-266.

10. Jones D, Song X, Mitniski A, Rockwood K. Evaluation of a frailty index finger based on a comprehensive geriatric assessment in a population based study of elderly Canadians. Aging Clin Exp Res. 2005;17:465-471.

11. Inouye K, Pedrazzani ES. Educational status, social economic status and evaluation of some dimensions of octogenarians' quality of life. Rev Lat Am Enfermagem. 2007;15:742-747.

12. Davis DH, Rockwood MR, Mitnitski AB, Rockwood K. Impairments in mobility and balance in relation to frailty. Arch Gerontol Geriatr. 2010;53:79-83.

13. Tinetti ME. Clinical practice. Preventing falls in elderly persons. N Engl J Med. 2003;348:42-49.

14. Shumway-Cook A, Baldwin M, Polissar NL, Gruber W. Predicting the probability for falls in community-dwelling older adults. Phys Ther. 1997;77:812-819.

15. Mathias S, Nayak USL, Isaacs B. Balance in elderly patients: the "get-up and go" test. Arch Phys Med Rehabil. 1986;67:387-389.

16. Fried LP, Tangen CM, Walston J, et al; for the Cardiovascular Health Study Collaborative Research Group. Frailty in older adults: evidence for a phenotype. J Gerontol A Biol Sci Med Sci. 2001;56:M146-M156.

17. Fautrelle L, Prablanc C, Berret B, Ballay Y, Bonnetblanc F. Pointing to double-step visual stimuli from a standing position: very short latency (express) corrections are observed in upper and lower limbs and may not require cortical involvement. Neuroscience. 2010;169:697-705.

18. Bleuse S, Cassim F, Blatt JL, et al. Effect of age on anticipatory postural adjustments in unilateral arm movement. Gait Posture. 2006;24:203-210

19. Yan JH, Thomas JR, Stelmach GE. Aging and rapid aiming arm movement control. Exp Aging Res. 1998;24:155-168.

20. Manckoundia P, Mourey F, Pfitzenmeyer P, Van Hoecke J, Pérennou D. Is backward disequilibrium in the elderly caused by abnormal perception of verticality? A pilot study. Clin Neurophysiol. 2007;118:786-793. 
21. Matheron E, Dubost V, Mourey F, Pfitzenmeyer P, Manckoundia P. Analysis of postural control in elderly subjects suffering from psychomotor disadaptation syndrome (PDS). Arch Gerontol Geriatr. 2010;5:e19-e23.

22. Barbieri G, Gissot AS, Pérennou D. Ageing of the postural vertical. Age (Dordr). 2010;32:51-60.
23. Shumway-Cook A, Brauer S, Woollacott M. Predicting the probability for falls in community-dwelling older adults using the Timed Up and Go Test. Phys Ther. 2000;80:896-903.

24. Tinetti ME, Speechley M, Ginter SF. Risk factors for falls among elderly persons living in the community. $N$ Engl J Med. 1988;319:1701-1707.

\section{Publish your work in this journal}

Clinical Interventions in Aging is an international, peer-reviewed journal focusing on evidence-based reports on the value or lack thereof of treatments intended to prevent or delay the onset of maladaptive correlates of aging in human beings. This journal is indexed on PubMed Central, MedLine, the American Chemical Society's 'Chemical Abstracts Ser-

\section{Dovepress}

vice' (CAS), Scopus and the Elsevier Bibliographic databases. The manuscript management system is completely online and includes a very quick and fair peer-review system, which is all easy to use. Visit http://www.dovepress.com/testimonials.php to read real quotes from published authors.

Submit your manuscript here: http://www.dovepress.com/clinical-interventions-in-aging-journal 